$7^{\circ}-18^{\circ} \mathrm{C}$. They were sorted into monthly groups and the standard sample measured varied from 50 to 200 from each of several trapping sites.

Each species measured has a maximum size in one of the winter months and a minimum in ono of the summer months with fairly steady intergrading. The extent of the variation is shown in the following data giving the maximum and minimum wing lengths in millimetres recorded in the samples and the percentage difference.

Metriocnemus longitarsus, $2 \cdot 66 \pm 0 \cdot 010$ in January 1939 to $2 \cdot 01 \pm 0.040$ in September 1938, 21 per cent difference.

Spaniotoma minima, $1.61 \pm 0.007$ in January 1939 to $1 \cdot 19 \pm 0.008$ in August 1938, 26 per cent difference.

Psychoda alternata, 2.58 \pm 0.022 in January 1938 to $1.86 \pm 0.016$ in June 1939,28 per cent difference.

Psychoda severini, $2.41 \pm 0.012$ in January 1939 to $1.89 \pm 0.013$ in June 1939,21 per cent difference.

The figures are complicated by the fact that competition, which is most intenso in the warmer months, also leads to a reduction in size, and samples taken at the same time from different positions on the beds may vary considerably according to the local composition and density of the population. It is evident, however, that temperature is the conditioning factor and that a rise of $1^{\circ} \mathrm{C}$. in the monthly mean entails a reduction in wing-length of the order of 1-2 per cent for each of the four species.

Mr. Glenny Smeal has kindly aided us in the statistical treatment of the data.

\section{H. Golighthy.} LL. LLOYD.

The University,

Leeds.

June 27.

1 Uvarov, B. P., Trans. Ent, Soc. Lond., 79, 35 (1931).

* Llosd, Ll., Proc. Roy. Ent. Soc. Lond., 10, 34 (1935); J. Inst. Seucage Purification, Part 1 (1937).

\section{The Mexican Loggerhead in Europe}

Trie valid scientific name of the Mexican loggerhead turtle, described as Thalassochelys (Colpochelys) kempi Garman 1880, is uncertain, since the animal is figured as Testudo caretta in the first specific account of a loggerhead ${ }^{1}$. Originally, Linnæus (1758) had conferred this name upon a now unrecognizable form he had attempted to describe by publishing a single family character.

My examination of specimens in 1938 revealed that the Mexican loggerhead is the western sub-species of a monotypic genus, its eastern relativo being described in 1829 from tho Pacific by Eschscholz as Chelonia olivacea. Boettger (1888) and Baur (1890) were the first to record the latter from the Atlantic, and in $1938 \mathrm{I}$ identified specimens from West Africa in the collections of the British Museum and Museum d'Histoire Naturelle, Paris 2 .

The costal scutes of the western form are more or less constant and arranged in five pairs; in the eastern sub-species their arrangement is usually asymmetrical, their numbers varying up to as many as nine, on one or both sides. The monotypic genus containing these two sub-species is characterized by four enlarged, pore-bearing inframarginal scutes, separating each side of the plastron from the carapace, and by the olive dorsal colour. The other genus of loggerhead is also monotypic with two sub-species, but possesses only three, poreless, inframarginals on each side and is brown-red dorsally. Both genera differ widely in osteology ${ }^{2,3}$.

The two sub-species do not overlap in distribution, consequently the recent discovery that the Mexican loggerhead is washed on to the British Isles" has given rise to considerable speculation as to the route and locality whence it arrived. Mr. H. W. Parker, of the British Museum, has suggested ${ }^{5}$ that individuals either drift eastwards with the Gulf Stream and West IVind Drift or that the distribution of this turtle is more extensive than is at present known, while $\mathrm{Dr}$. F. S. Russell ${ }^{6}$ has suggested that the northward extension of the warm area of the Atlantic might bring these turtles into regions where they could be carried to the British Isles by the surface drift.

Tho more or less uniform size of the three individuals I identified at the Dublin and British Musoums in 1938 suggests that newly hatched young aro transported from one and the same locality, and by the time they are stranded off the British Isles have just about reached sexual maturity, although they have by no means attained to their maximum size. The question of the locality whence they were transported is partially answered by my recent discovery of a young specimen from the Azores?, which supports Parker's view that this turtlo possesses a wider distribution than is generally known.

It is probable that while individuals from the Azores travel northward with the extension of the warm area of the Atlantic, and are swept to the British Isles, others are transported from the Gulf of Mexico. Marking experiments both at the Azores and the Gulf of Mexico alone will solve the problem.

\section{P. Deraniyagala.}

Colombo Museum, Ceylon.

1 Schoepf, "Historia Testudinum" (1792).

Deranisagala, Spolia Zeylanica, 18, 61 (1933).

IIay, Proc. U.S. Nat. Mfus., 34, 183 (1908).

- Deraniyagala, Nature, 142, 540 (1938).

s Parker, Proc. Linn. Soc.,'151, 127 (1939).

- Russell, Niture; 143, 206 (1939).

'Deraniyagala, Bull. Institut Oceanographique, 772 (1939).

The discovery of Kemp's loggerhead in the Azores is of considerable interest, but we obviously still need much more information before we can do more than guess at the causes underlying the movements of these turtles. Among other things, it is essential to discover whether the species is resident around these western islands, for it is quite possible that the single young one found there is a stray similar to those which reach the British coast. The Azores, like the British Isles, lie within the area to which larval eels are carried from their breeding grounds in the. western Atlantic. Is it possible that there may be a correlation between the migration of Leptocephalus and the movements of these turtles ? Or is it a coincidence that 'glass-eels' (larval stage 5) appear off the Spanish coast in September and October, off Ireland in November, and that turtles are stranded on the south-western coast of Great Britain in November and December?

Another point raised which may prove to be significant is the fairly uniform immature size of the examples of Kemp's loggerhead which reach our coast. The three additional specimens exarnined by 